ELECTRONIC LETTER

\title{
Mutation screening of Mrel1 complex genes: indication of RAD50 involvement in breast and ovarian cancer susceptibility
}

\author{
K Heikkinen, S-M Karppinen, Y Soini, M Mäkinen, R Winqvist
}

J Med Genet 2003;40:e131 (http://www.jmedgenet.com/cgi/content/full/40/12/e131)

A pproximately $5-10 \%$ of all breast and ovarian cancers are due to genetic predisposition. ${ }^{1}$ Germline mutations in two major susceptibility genes, BRCAI and BRCA2, explain most of the hereditary ovarian cancer cases, but worldwide have been observed only in a fraction of the breast cancer families; in Finland, about $20 \%{ }^{2-4}$ A small portion of the remaining cases, perhaps $1-2 \%$, appears to be caused by germline mutations in other cancer susceptibility genes such as TP53, PTEN, AR, and ATM..$^{5}$ Recently, moderate or low penetrance germline mutations such as l100delC of CHK2 have also been implicated, ${ }^{6}$ suggesting that in many cases the phenotypic expression of the disease is accounted for by the combined effect of multiple but more subtle mutations in different target genes. ${ }^{57}$ Despite all these discoveries, many breast cancer families, especially those with fewer than four cases and/or with later disease onset, have cancers due to mutations in still unknown genes. As the protein products of the genes so far indicated are central players in the pathways involved in cell cycle checkpoint functions and in the sensing, transduction, and repair of DNA lesions, ${ }^{5}$ other similarly acting genes may represent new potential candidates for breast and/or ovarian cancer susceptibility.

The Mrell complex, composed of the proteins MREll, NBS1, and RAD50, is a vital component in the DNA damage response and is at least partially responsible for connecting DNA damage detection to DNA repair and cell cycle checkpoint functions. The early association of the complex with damaged DNA suggests its involvement in sensing DNA double strand breaks (DSBs). In eukaryotes, DSB repair is handled by two different pathways, homologous recombination (HR) and non-homologous end joining (NHEJ), and the initial step in both is the recognition and signalling of the damage by the Mrell complex. ${ }^{8-10}$ In addition to DNA damage detection and repair, the complex has an important role in co-ordinating checkpoint responses and DNA replication, ${ }^{11-14}$ and is also required for the maintenance of telomeres. $^{15}$

The sites important for the composition and various functional activities of the Mrell complex have been characterised (summarised in fig 1). Because of its independent interaction with both NBS1 and RAD50, MRE11 has been viewed as the core of the complex, whereas the interaction between NBS1 and RAD50 is indirect and mediated through MRE11.9 ${ }^{16} 17$ The sites in MREll responsible for binding to NBS1 and RAD50 have both been assigned to the aminoterminal half of the protein. ${ }^{16}{ }^{18}$ In NBS1, the MRE1l binding domain has been located to the extreme carboxyterminus of the protein, ${ }^{16}$ and the corresponding site in RAD50 has been located to a 40 residue coiled coil region adjacent to the ABC domain. ${ }^{19} 20$ Additionally, several other important domains for the complex function have been identified. The DNA nuclease activity is restricted to MRE11 and specified by phosphodies-

\section{Key points}

- The Mre 11 complex has an essential role in maintaining genomic integrity and preventing cells from malignancy. The complex components interact with several proteins (for example BRCA1, ATM and CHK2) already connected to hereditary breast and ovarian cancer susceptibility, which makes MRE 1 1, NBS1, and RAD50 suitable candidate genes for predisposition to these cancers.

- We screened the affected index cases of 151 families with signs of hereditary susceptibility to breast and/or ovarian cancer for germline mutations in the Mrel1 complex genes. Seven novel heterozygous alterations were observed, three of which were considered potentially disease-related: MRE 11 913C $\rightarrow$ T (Arg305Trp), NBS1 448C $\rightarrow$ T (Leu150Phe) and RAD50 687delT (stop codon at 234).

- RAD50 687delT is expected to cause major truncation in both known protein isoforms and occurs in multiple individuals of two families. Curiously, RAD50 687delT was also present in some of the controls, but at a lower frequency, probably referring to incomplete penetrance. The MREII and NBS1 alterations affected highly conserved amino acids and were seen in single cancer cases, but they were both absent in 1000 healthy controls.

- Our results suggest that these three mutations in the Mrel1 complex genes associate with hereditary susceptibility to breast and/or ovarian cancer, and may be important in other types of cancer too. This is the first time to our knowledge that germline mutations in RAD50 have been linked to genetic disease in humans.

terase motifs in the aminoterminal half of the molecule. ${ }^{18}$ The aminoterminus of NBS1 exhibits a forkhead associated (FHA) domain, followed by a BRCAl carboxyterminal (BRCT) domain..$^{21}$ Both of these highly conserved domains are involved in protein-protein interactions and are therefore crucial for the functions of the Mrell complex, including its

Abbreviations: $A T$, ataxia telangiectasia; $A T L D$, ataxia telangiectasialike disorde; BASC, BRCA1 associated genome surveillance complex; $B R C T, B R C A 1$ carboxyterminus; CSGE, conformation sensitive gel electrophoresis; DSB, double strand break; FHA, forkhead associated; HR, homologous recombination; NBS, Nijmegen breakage syndrome; NHEJ, non-homologous end joining 
subcellular localisation after DNA damage. ${ }^{17}{ }^{22}$ RAD50 in turn consists of bipartite $\mathrm{N}$ - and C-terminal ATPase segments, which assemble into a single ABC-type cassette at the end of the predicted antiparallel coiled coil. ${ }^{19}$ A functionally important zinc hook has been identified in the central portion of the coiled coil domain. ${ }^{23}$ This zinc hook is thought to mediate RAD50 dimerisation, which allows the required molecular flexibility of the Mrell complex and keeps it functionally assembled during the DNA recombination and repair process. ${ }^{14}$

The Mrell complex proteins interact with several important protein partners, many of which have been related to cancer predisposition. For instance, following ionising radiation, NBS1 is phosphorylated in an ATM dependent manner to ensure proper response to DNA damage. ${ }^{11}$ In turn, MREll phosphorylation relies on NBS1.24 Co-operation between a functional Mrell complex and ATM is also required for activation of the CHK2 kinase in response to DNA damage. ${ }^{12}$ In addition, MRE11, NBSI and RAD50 are linked through protein-protein interactions with BRCAl. After exposure to ionising radiation, BRCAl forms nuclear foci that co-localise with the Mrell complex. ${ }^{25}$ Along with BRCAl, ATM, and other proteins, MRE11, NBS1, and RAD50 are also part of a multi-subunit protein complex referred to as the BRCAl associated genome surveillance complex (BASC). ${ }^{26}$

Failure in the DNA damage response and repair processes causes chromosomal instability that may result in cancer predisposition. For two of the Mrell complex genes, namely MRE11 and NBS1, the connection to cancer has already been established: germline mutations in MRE11 are associated with the ataxia telangiectasia-like disorder (ATLD), ${ }^{27}$ whereas defects in NBSI cause Nijmegen breakage syndrome (NBS). ${ }^{921}$ Cells derived from ATLD and NBS patients display similar characteristics as those from ataxia telangiectasia (AT) patients, and AT due to germline mutations in the ATM gene has been associated with an increased risk of developing various malignancies; breast cancer, lymphoma, and leukaemia in particular. ${ }^{28}$ As yet, germline mutations in RAD50 have not been connected to genetic diseases in humans. However, in mice certain germline RAD50 mutations result in growth defects and cancer predisposition. ${ }^{29}$ Because mutations in $A T M, C H K 2$, and BRCAI have all been previously linked to hereditary predisposition to breast and/or ovarian cancer ${ }^{5}$ it is possible that germline mutations in the individual Mrell complex genes may also be directly involved in predisposition to these cancers. The suggested connection has been supported by a recent study, where the NBS1 657del5 founder mutation was found to be responsible for the occurrence of a small but significant portion of familial breast cancer cases. ${ }^{30}$

On these grounds, we tested 151 index patients from Finnish families with signs of hereditary susceptibility to breast and/or ovarian cancer for possible germline mutations in the MRE11, NBS1, and RAD50 genes. The results of our study indicate novel disease associated alterations.

\section{MATERIALS AND METHODS}

\section{Subjects and unaffected controls}

Index cases diagnosed with breast or ovarian cancer of 151 families originating from northern Finland were selected for the screening of germline MRE11, NBS1, and RAD50 mutations. Of the studied families, 95 were associated with breast, 29 with breast-ovarian, and 4 with ovarian cancer. These families met the criteria for either high (76 families) or moderate ( 52 families) genetic susceptibility to breast and/or ovarian cancer. Inclusion criteria for the families were one or more of the following: (a) two to three or more cases of breast and/or ovarian cancer in first or second degree relatives; $(b)$ early disease onset ( $\leqslant 35$ years); $(c)$ bilateral breast cancer;

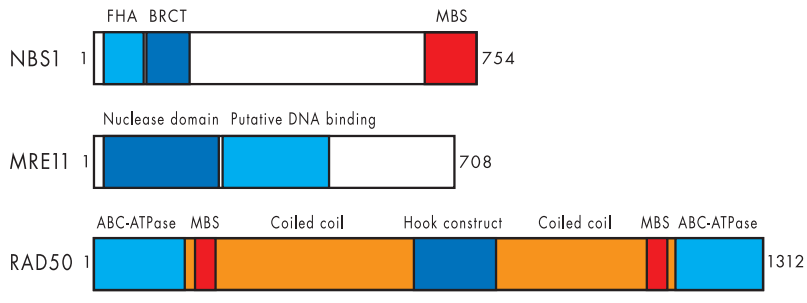

Figure 1 Components of the Mre 11 complex. The functional domains of each protein are marked above the corresponding diagram (see text for more details). In addition, the putative DNA binding domain ${ }^{20}$ (NCBI: LocusLink) of MRE 11 and the RAD50 hook construct containing the zinc binding Cys-X-X-Cys-motif ${ }^{23}$ are shown. FHA, forkhead associated; BRCT, BRCA1 carboxyterminal; MBS, MRE1 1 binding sites.

or $(d)$ multiple primary tumours including breast or ovarian cancer in the same individual. The high risk families mainly included three or more cancer cases. All of the high risk families had been screened for germline mutations in BRCAl, $B R C A 2, C H K 2$, and TP53, and eleven of them were found to be BRCA1 or BRCA2 mutation positive. ${ }^{431} 32$ Besides high or moderate risk families, 23 families showing single cases of breast or ovarian cancer along with multiple cases (two or more) of other kinds of cancer in first or second degree relatives were included in the study. Additionally, 1000 anonymous cancer free individuals were used as controls, and the occurrence of novel, potentially pathogenic alterations was also investigated in 192 breast cancer patients without family history of the disease. Both groups derived from the same geographical area as the studied families. All patients had given their informed consent for obtaining pedigree data and blood specimens for a study on cancer susceptibility gene mutations. Approval to perform the study was obtained from the ethics board of the Northern Ostrobotnia Health Care District and the Finnish Ministry of Social Affairs and Health.

\section{Screening for germline mutations}

DNA from blood lymphocytes was extracted using the standard phenol-chloroform method or the Puregene D$50 \mathrm{~K}$ purification kit (Gentra, Minneapolis, MN, USA). The coding regions and exon-intron boundaries of the MRE11, NBS1, and RAD50 genes were screened for germline mutations by conformation sensitive gel electrophoresis (CSGE), which has been shown to be a cost efficient way to scan genes with high sensitivity and specifity. ${ }^{33}$ Samples with band shift were reamplified and the sequencing analysis was performed with the Li-cor IR ${ }^{2} 4200-S$ DNA Analysis system (Li-cor Inc., Lincoln, NE, USA) using the SequiTherm EXEL $^{\mathrm{TM}}$ II DNA Sequencing kit LC (Epicentre Technologies, Madison, WI, USA). Oligonucleotides for CSGE and sequencing were designed by using Primer3 software based on sequence information obtained from publicly available databases. Oligonucleotide sequences and PCR conditions are available upon request.

\section{LOH analysis}

Loss of heterozygosity ( $\mathrm{LOH})$ analysis was performed to assess whether the tumours of the patients displaying the novel MRE 11 and RAD50 germline mutations had lost the wildtype allele. The flanking microsatellite DNA markers used for MRE11 were DIIS4176 and DIIS1757; and for RAD50 D5S2110, D5S2057, D5S1984, D5S2002, and D5S2117. The PCR products were analysed with the Li-cor DNA Analysis system using the IRD800 labelled forward primer. 
Table 2 Observed sequence variants occurring in the exon regions of the Mre 11 complex genes

\begin{tabular}{|c|c|c|c|c|c|}
\hline \multirow[b]{2}{*}{ Gene } & \multirow[b]{2}{*}{ Exon } & \multirow[b]{2}{*}{$\begin{array}{l}\mathrm{Nt} \\
\text { change }\end{array}$} & \multirow[b]{2}{*}{$\begin{array}{l}\text { Effect on } \\
\text { protein }\end{array}$} & \multicolumn{2}{|l|}{ Allele frequency* } \\
\hline & & & & $\begin{array}{l}\text { Hereditary } \\
\text { cases }\end{array}$ & Controls \\
\hline \multirow[t]{5}{*}{ NBS1 } & 2 & $102 \mathrm{G} \rightarrow \mathrm{A}$ & Leu34Leu† & $39.1 \%(59 / 151)$ & ND \\
\hline & 5 & $553 \mathrm{G} \rightarrow \mathrm{C}$ & Glu185GIn† & $43.7 \%(66 / 151)$ & ND \\
\hline & 10 & $1197 T \rightarrow C$ & Asp399Asp† & $50.3 \%(76 / 151)$ & ND \\
\hline & 11 & $1720 \mathrm{~A} \rightarrow \mathrm{T}$ & Leu574lle & $0.7 \%(1 / 151)$ & $1.3 \%(4 / 307) \ddagger$ \\
\hline & 13 & $2016 \mathrm{G} \rightarrow \mathrm{A}$ & Pro672Pro† & $37.1 \%(56 / 151)$ & ND \\
\hline \multirow[t]{3}{*}{ RAD50 } & 2 & $204 C \rightarrow T$ & His $68 \mathrm{His}$ & $0.7 \%(1 / 151)$ & ND \\
\hline & 3 & $280 A \rightarrow C$ & lle94Leu & $1.3 \%(2 / 151)$ & $0.3 \%(3 / 1000)$ \\
\hline & 5 & $671 \mathrm{G} \rightarrow \mathrm{A}$ & Arg224His & $2.0 \%(3 / 151)$ & $0.9 \%(9 / 1000)$ \\
\hline
\end{tabular}

\section{Evaluation of RAD50 687 delT expression at the mRNA level}

Expression of the mutated allele at the mRNA level was evaluated for RAD50 687delT. Using the FastTrack ${ }^{\circledR} 2.0$ Kit (Invitrogen, Carlsbad, CA, USA), mRNA from lymphoblast cell lines was isolated, following which cDNA synthesis was carried out with the GeneRacer ${ }^{\mathrm{TM}}$ kit (Invitrogen). The use of the GeneRacer ${ }^{\mathrm{TM}}$ Kit ensured that only transcripts containing full length cDNA ends were used in PCR analysis. Primers used for the cDNA specific amplification of RAD50 exon 5 were: forward 5'-TTTGAAGCAAAAGTTTGATGAGA-3' (located in exon 4) and reverse 5' TCATTGTCAAGTTTCATTATTTTAGAG-3' (located in exon 6).

\section{RESULTS}

\section{Novel germline alterations}

The mutation analysis of the MRE11, NBS1, and RAD50 genes revealed several germline alterations. Eleven heterozygous changes in protein encoding regions were observed (summarised in tables 1 and 2). Seven of the alterations were novel and three of these were considered potentially disease related. In addition, a large number of different apparently harmless alterations occurring in intron regions was seen (data not shown).

\section{MRE 11 and NBS 1}

In the MRE 11 gene, a single mutation in exon 10 was found in one index case with ovarian cancer (case 322, fig 2A). This novel single base change, a transition $\mathrm{C} \rightarrow \mathrm{T}$ at position 913 , resulted in substitution of arginine to tryptophan at codon 305. The position of the involved arginine is extremely conserved between several species, even those distantly related (fig 4) (yeast and flowering plant: data not shown). Additionally, the flanking regions on both sides of this residue are well conserved, suggesting functional importance.

In contrast to MRE11, multiple alterations within the protein encoding region of NBSI were detected, but only one was considered potentially pathogenic. This novel change, a
$\mathrm{C} \rightarrow \mathrm{T}$ transition at nucleotide 448 , results in substitution of leucine to phenylalanine at codon 150 and was displayed by one index case diagnosed with breast cancer (case 277, fig 2B). Interestingly, this alteration occurs in the middle of the highly conserved BRCT domain, where the leucine residue at position 150 is conserved also in the mouse, rat, and chicken orthologues (fig 4).

Both the MRE11 and NBSI mutations were observed in single multi-cancer families including one ovarian or one breast cancer case, respectively, but co-segregation with the cancer phenotype could not be confirmed owing to lack of DNA specimens from additional family members. However, both of the mutations were absent from a large cohort of population controls $(n=1000)$, indicating that these mutations may indeed relate to cancer predisposition (table 1).

\section{RAD50}

In $R A D 50$, four novel germline changes affecting exon regions were discovered (tables 1 and 2). Of these changes, His68His appears to be a harmless polymorphism, but the roles of Ile94Leu and Arg224His alterations remain more difficult to determine. Both of these substitutions affect conserved residues, the former in the remarkably well conserved aminoterminal ATPase domain and the latter in the coiled coil domain, 1920 but they also occurred in the healthy controls, although at lower frequency. Interestingly, one of the breast cancer families displaying the RAD50 Ile94Leu variant also showed partial co-segregation with the previously identified CHK2 Ile157Thr unknown variant. ${ }^{31}$ Until further clarifying studies have been carried out, the cancer predisposing role of these two RAD50 variants remains unknown. However, at least one of the identified RAD50 alterations, $687 \mathrm{delT}$, is likely to be disease related.

\section{The RAD50 687delT truncation mutation}

The RAD50 687delT mutation in exon 5 leads to a premature stop at codon 234 and affects both isoforms of the protein.

Table 1 Novel MRE11, NBS1 and RAD50 mutations

\begin{tabular}{|c|c|c|c|c|c|c|}
\hline \multirow[b]{2}{*}{ Gene } & \multirow[b]{2}{*}{ Exon } & \multirow[b]{2}{*}{ Nt change } & \multirow[b]{2}{*}{ Effect on protein } & \multicolumn{3}{|l|}{ Allele frequency* } \\
\hline & & & & Hereditary cases & Sporadic cases & Controls \\
\hline MRE 11 & 10 & $913 C \rightarrow T$ & Arg305Trp & $0.7 \%(1 / 151)$ & $-(0 / 192)$ & $-(0 / 1000)$ \\
\hline NBS1 & 4 & $448 C \rightarrow T$ & Leu150Phe & $0.7 \%(1 / 151)$ & $-(0 / 192)$ & $-(0 / 1000)$ \\
\hline RAD50 & 5 & 687delT & $\begin{array}{l}\text { Frameshift } \rightarrow \text { stop } \\
\text { codon at } 234\end{array}$ & $1.3 \%(2 / 151)$ & $-(0 / 192)$ & $0.6 \%(6 / 1000)$ \\
\hline
\end{tabular}


A MRE 11 Arg305Trp

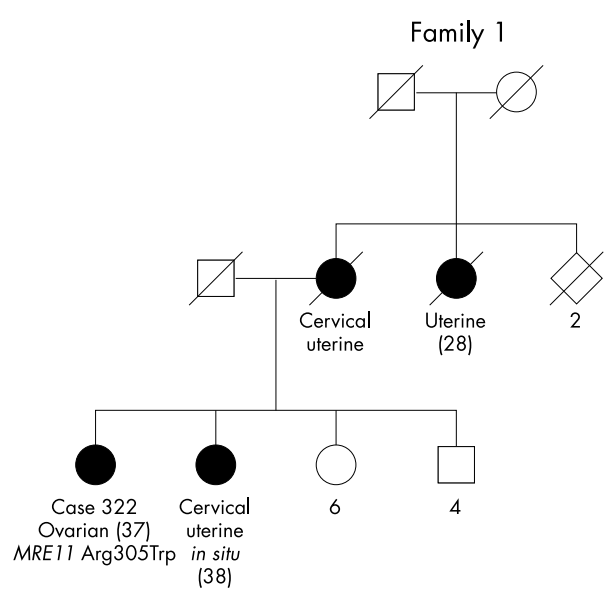

B NBS1 Leu150Phe

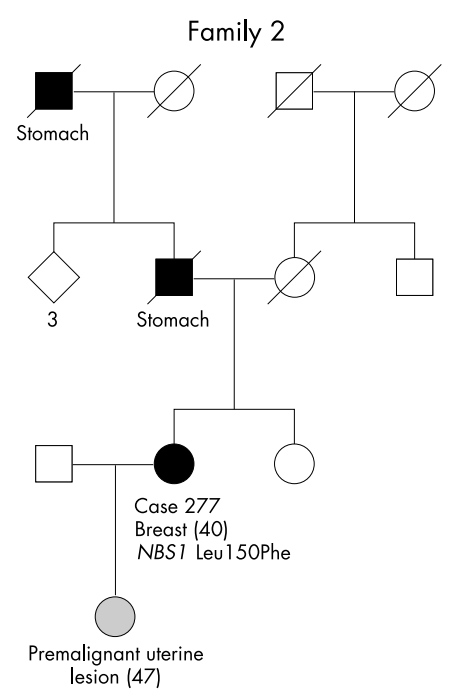

Figure 2 Families exhibiting the novel (A) MRE 11 Arg305Trp and (B) NBS1 Leu150Phe germline mutations. Black circles (females) and boxes (males) indicate individuals with cancer. The grey filling indicates a pre-malignant esion. The age at diagnosis, when known, is marked after the disease. The case number of individuals tested for a mutation is shown.
The deletion was found in two separate families (fig 3). In family 5, the index case and her sister (cases 828 and 474), both diagnosed with breast cancer, were carriers of the mutation. In family 6 , the index (case 505) with ovarian cancer carried RAD50 687delT, but had also tested positive for the BRCAl 3745delT mutation in one of our previous studies. ${ }^{4}$ In addition, the deceased mother with ovarian cancer was an obligatory carrier of at least the RAD50 687delT mutation. In all the other cases tested, both the RAD50 and the BRCAI truncation mutation segregated incompletely with the disease.

The observation of unaffected RAD50 truncation mutation carriers in family 6 , and also the surprisingly high prevalence at the population level $(0.6 \%)$ suggested not only that RAD50 687delT, if truly pathogenic, exhibits low penetrance, but also that it might predispose carriers to cancer without clustering of the disease in the pedigrees. In order to test this hypothesis, we screened 192 breast cancer cases without family history of the disease for the RAD50 truncation mutation. In parallel, we also screened the same cases for the MRE 11 and NBS1 mutations, as the disease segregation of these two alterations could not be confirmed from the pedigrees. As none of the tested alterations was observed in the studied cohort, it may suggest that these changes are mainly associated with patients with a family history of cancer.

As $R A D 50$ 687delT is expected to cause truncation of most of the protein product, we evaluated whether these mutant transcripts are eliminated by nonsense mediated decay. Lymphoblast cell lines generated from blood specimens of three different mutation positive individuals (fig 3 : family 5 , case 828; family 6, cases 505 and 061) was used to produce mRNA for the cDNA synthesis. The results from sequencing analysis unambiguously demonstrated that in all studied cases both the wild type and the truncation allele were still present in the tested mRNA pool (data not shown).

\section{MRE 11 and RAD50 LOH analysis}

In order to test the nature of the observed mutations, we investigated whether the tumorigenesis thought to be
RAD50 687delT

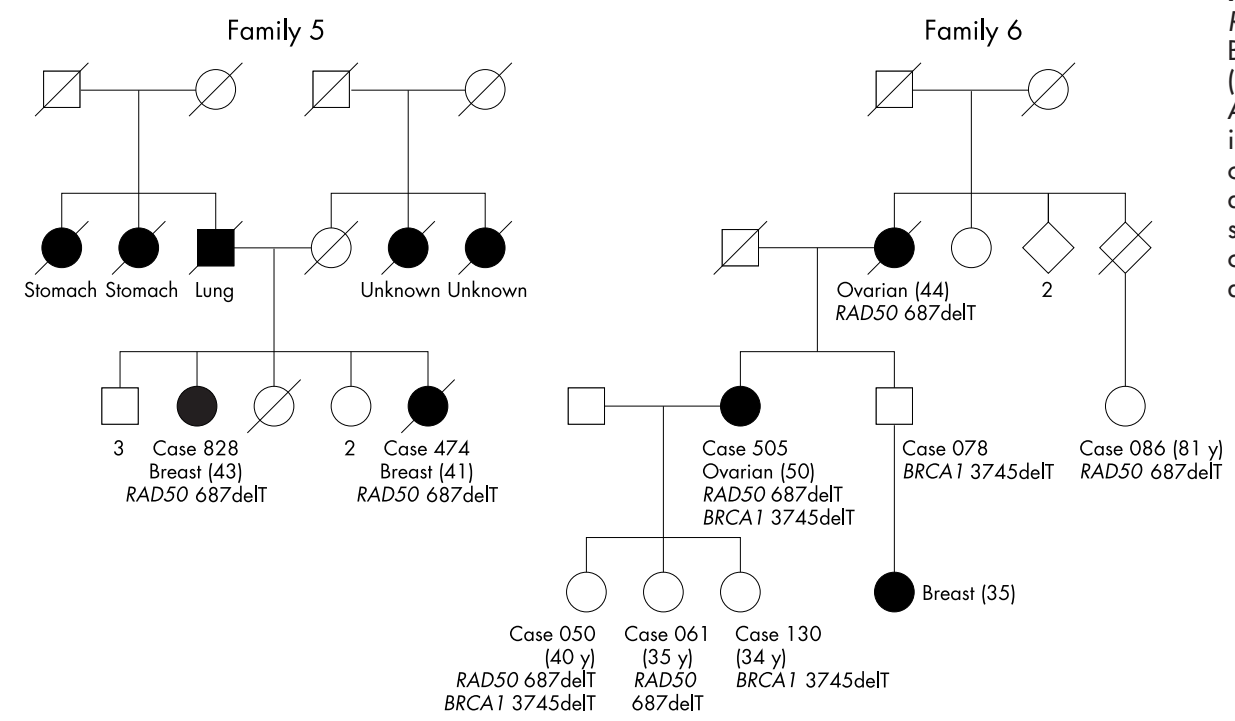

Figure 3 Families with the novel RAD50 687delT germline mutation. Black circles (females) and boxes (males) indicate individuals with cancer. Age at diagnosis, when known, is indicated after the malignancy. The case number of individuals analysed and with parallel genetic changes is shown. For a disease free mutation carrier, the age at monitoring is shown after the case number. 


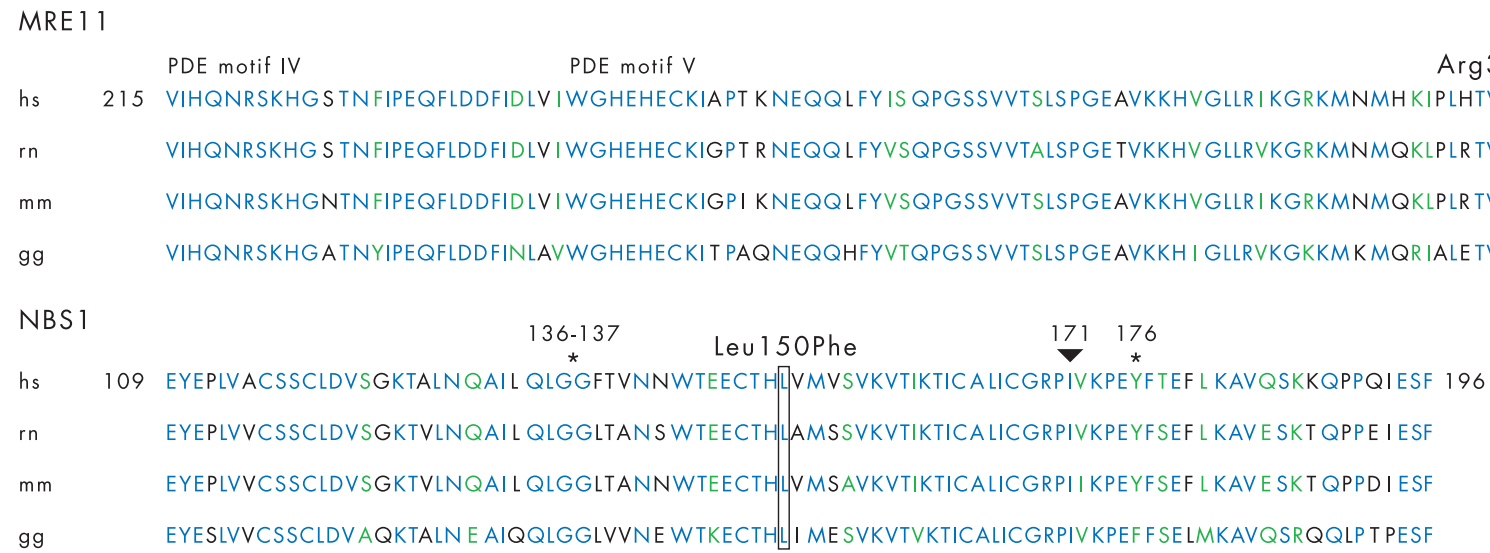

Figure 4 Novel amino acid substitutions in MRE1 1 and NBS1, and comparison of sequence homology between Homo sapiens (hs), Rattus norvegicus ( $\mathrm{rn})$, Mus musculus (mm) and Gallus gallus ( $\mathrm{gg})$. The sites showing changed residues are boxed. The amino acids conserved in all four species are drawn in blue, biochemically similar residues in green, and dissimilar ones in black. The sequence shown for MRE 11 extends to its last two phosphodiesterase motifs (PDE IV and V) ${ }^{18}{ }^{38}$ and for NBS1 corresponds to its BRCT domain. ${ }^{22}$ In NBS1 the two sites (136-137 and 176) marked with an asterisk (*) have been found to be critical for Mre 11 complex nuclear focus formation and phosphorylation of NBS1 after irradiation, ${ }^{40}$ and the one marked with an arrowhead $(171 \nabla)$ has been associated with acute lymphoid leukaemia. ${ }^{39}$

associated with the novel germline mutations involved loss of the corresponding wild type allele. LOH analysis was performed on the available tumour specimens from four different patients (cases 322, 828, 474, and 505; figs 2 and 3) displaying either the MRE11 or RAD50 mutation, but no $\mathrm{LOH}$ was observed (data not shown). Owing to the lack of suitable tumour material the corresponding $\mathrm{LOH}$ analysis for the NBSI mutation could not be performed.

\section{DISCUSSION}

The Mrell complex is an integral part of the proper DNA damage response and repair of double strand breaks, essential for the wellbeing of any living organism. Failure in these highly conserved processes leads to the loss of genomic integrity and consequently to an elevated risk of cancer. ${ }^{14}$ The cellular functions of the Mrell complex are indispensable, as seen in mice, where major deficiencies in any of the mrell, nbs 1 , or rad50 genes cause early embryonic lethality and only hypomorphic mutations appear to be viable. ${ }^{34-36}$ In humans, only a small number of hypomorphic germline mutations affecting the MRE 11 and NBSI genes are currently known, mainly associating with the severe and cancer prone phenotypes of ATLD and NBS, respectively. ${ }^{21} 2737$ Disease related germline mutations in RAD50 have not to our knowledge previously been reported.

In the current study, we have examined the prevalence of NBS1, MRE 11, and RAD50 germline mutations in index cases with breast or ovarian cancer from 151 families. Of the novel heterozygous sequence alterations observed, Arg305Trp (MRE11), Leul50Phe (NBSI), and 687delT (RAD50) potentially relate to cancer susceptibility (table 1). As the $\mathrm{LOH}$ analysis of tumours from MRE11 or RAD50 mutation carriers showed retention of the wild type alleles, it may indicate that these germline mutations are sufficient to cause the observed adverse phenotypic effect. However, silencing of the wild type allele by epigenetic mechanisms (for example by promoter region hypermethylation) cannot be excluded.

The association of the novel MREII and NBSI missense mutations with hereditary cancer susceptibility is supported by their absence in both the controls and the unselected breast cancer cases. In addition, both amino acid substitutions occur in highly conserved protein domains. In MRE11, the Arg305Trp substitution takes place at the very end of the first of two major protein domains ${ }^{20}$ replacing the conserved positively charged hydrophilic arginine with the neutral and highly hydrophobic tryptophan. Because of its position in the protein, it is possible that the Arg305Trp substitution may affect the structural organisation of the functionally active $\mathrm{L}$ shaped groove located between domains 1 and $2,{ }^{38}$ and perhaps lower the affinity of MREll for DNA binding. The situation could be similar to that indicated for the Asnl17Ser mutation in ATLD; ${ }^{27}$ despite the fact that the change occurs relatively remote from the active site, it has been suggested to disturb the macromolecular interaction of MRE $11 .{ }^{20}$ In NBS1, the Leul50Phe substitution involves the highly conserved BRCT domain (fig 4), where the conserved leucine is replaced with the biochemically non-similar phenylalanine. Interestingly, another amino acid substitution affecting a conserved residue in the BRCT domain, Ilel71Val, has previously been associated with cancer (acute lymphoblastic leukaemia). ${ }^{39}$ Additionally, recent site specific mutagenesis experiments by Cerosaletti \& Concannon $^{40}$ indicate that changes at the conserved residues GlyGly136-137GluGlu or Tyr 176Ala are capable of disrupting Mrell complex nuclear focus formation and blocking NBSI phosphorylation after irradiation, emphasising the functional importance of this region and especially the role of the conserved amino acids in the BRCT domain. However, in order to obtain proof of the proposed deleterious nature of the MRE 11 and NBSI missense mutations discovered in the current study, the biochemical effects of these alterations has to be demonstrated by functional assays. Furthermore, additional case-control series are needed to confirm their possible role of as cancer susceptibility alleles.

Of the novel germline alterations observed in this study, RAD50 687delT was probably the most dramatic as it is predicted to cause about $80 \%$ shortening of both isoforms of the protein. The truncated protein would have retained only the N-terminal portion of the sequence necessary for binding of the RAD50 dimer to MRE11, but would have lost the corresponding and equally important C-terminal site. ${ }^{23}$ Based on studies of lymphoblast cell lines we know that the deletion allele is expressed at the mRNA level, but it is currently unknown if it actually gives rise to a truncated protein, how stable this product would be, and whether it has effects on the function of the wild type protein, perhaps by disturbing the functionally important dimerisation of RAD50. If a shortened protein actually is produced, but is unstable, the effect is likely to be that of a null mutation. This dosage variation due to haploinsufficiency may have a direct 
influence on the activities in DNA damage recognition and response pathways, and could modify the cancer risk by increasing genetic instability or by altering the effect of the normal DNA damage response. ${ }^{41}$ However, the possibility that $R A D 50687 \mathrm{delT}$ is a hypomorphic mutation, analogous to the common Slavic NBS founder mutation NBS1 657del $5,{ }^{42}$ also cannot be excluded. Interestingly, according to the recent study by Gorski et al, the frequency of the NBSI 657 del5 mutation in the population controls they used is comparable with that of RAD50 687delT in our study (both $0.6 \%$ ).

The RAD50 687delT mutation was observed altogether in seven individuals, two of whom showed breast and two ovarian cancers, all at relatively young age (41-50 years old). However, in family 6 (fig 3 right) the situation is less straightforward, as at least one of the affected individuals (case 505) showed parallel involvement of the previously identified BRCA1 3745 delT truncation mutation. ${ }^{4}$ In addition, there were several unaffected carriers of both mutations, but the three daughters of case 505 found positive for either the $R A D 50$ or the BRCAl mutation, or both, may not yet contribute to the understanding of the disease penetrance owing to their relatively young age. Although at present it is difficult to determine the exact role of these two germline mutations in this family, there are several scenarios worth exploring. It is possible that both RAD50 and BRCAl act independently on the resultant phenotype. On the other hand, co-occurrence of RAD50 687delT could also strengthen the effect of the BRCAI mutation. Interestingly, a recent comparative genome hybridisation targeted linkage analysis has revealed a possible BRCAl penetrance modifier locus on $5 \mathrm{q}$ in a location close to $R A D 500^{43}{ }^{44}$ Besides penetrance modification, the RAD50 mutation may also in some way influence the tissue specificity of a BRCAl associated malignancy. However, it is also possible that in the genetic background provided by this particular family the mutation in $R A D 50$ does not significantly increase the risk of cancer in BRCA1 3745delT carriers.

The surprisingly high frequency of RAD50 687delT mutation carriers among the healthy population controls and its absence from the breast cancer cases without familial disease background suggests that RAD50 687delT may be a new low penetrance susceptibility allele associated particularly with hereditary predisposition to cancer. At present it is unknown whether the RAD50 687delT allele exists outside Finland, as it is a well known fact that many disease related gene defects can be either unique or highly enriched in the Finnish population, owing to founder effects, isolation, and genetic drift. ${ }^{45}$ However, the situation could also be similar to that observed for the cancer predisposing CHK2 1100delC allele, which is enriched in southern Finland, ${ }^{31} 46$ but also occurs at significant frequencies in many other European populations (for example, the $\mathrm{UK}^{6}$ ). In order to obtain more information about the geographical occurrence and the overall relevance of the RAD50 687delT mutation, the intention is to study additional breast, ovarian, and other hereditary cancer materials along with suitable control specimens, initially from the Nordic countries. In addition, functional studies are needed to reveal the exact details about the molecular consequences of the RAD50 687delT mutation. In conclusion, this is the first time that germline mutations in RAD50 have been linked to genetic diseases in humans. The RAD50 deletion allele reported in this study provides evidence that deleterious germline mutations in the third member of the Mrell complex exist, are viable, and appear to associate with predisposition to cancer. Additional investigations will be needed to confirm and follow up these preliminary leads on the role of Mrell complex gene mutations in hereditary susceptibility to cancer.

\section{ACKNOWLEDGEMENTS}

The authors wish to thank Drs G Blanco, U Puistola, J Leisti and J Ignatius, and Nurse O Kajula for their help in patient contacts. We are grateful to Dr $\AA$ Borg and K Rapakko MSc for comments on the manuscript, and to Dr M Allinen for contribution in the early phases of this study. The expertise and helpfulness of Dr M Heikkinen in several clinical issues is highly appreciated. We are most thankful for the skilful assistance of K Outila in performing part of the mutation screening work. We wish to thank the Academy of Finland, University of Oulu, Oulu University Hospital, Nordic Cancer Union, and the Cancer Foundation of Northern Finland for providing the means for the current investigation. The kind participation of all patients has been of utmost importance for performing this study.

\section{ELECTRONIC DATABASE INFORMATION}

NCBI Entrez Genome, http://www.ncbi.nlm.nih.gov/mapview/map_ search.cgi.

The accession numbers are: AP000786, NM_005590 and NM_005591 for MRE11; AB013139 and NM_002485 for NBS1; NT_007072, NM 005732 and NM 133482 for $\overline{R A D} 50$.

NCB্ LocusLink, http://www.ncbi.nlm.nih.gov/LocusLink/.

SNP database, http://www.ncbi.nlm.nih.gov/SNP.

Primer3 software, http://www-genome.wi.mit.edu/cgi-bin/primer3 www.cgi.

\section{Authors' affiliations \\ K Heikkinen, S-M Karppinen, R Winqvist, Departments of Clinical Genetics}

Y Soini, M Mäkinen, Pathology, University of Oulu, Oulu University Hospital, Oulu, Finland

Correspondence to: Dr R Winqvist, Department of Clinical Genetics, Oulu University Hospital, PO Box 24, FIN-90029 OYS, Finland; robert.winqvist@oulu.fi

\section{REFERENCES}

1 Rahman N, Stratton MR. The genetics of breast cancer susceptibility. Annu Rev Genet 1998:32:95-121.

2 Vehmanen P, Friedman LS, Eerola H, Sarantaus L, Pyrhönen S, Ponder BJA, Muhonen T, Nevanlinna H. A low proportion of BRCA2 mutations in Finnish breast cancer families. Am J Hum Genet 1997:60:1050-8.

3 Vehmanen P, Friedman LS, Eerola H, McClure M, Ward B, Sarantaus L, Kainu T, Syriäkoski K, Pyrhönen S, Kallioniemi OP, Muhonen T, Luce M, Frank TS, Nevanlinna H. Low proportion of BRCA1 and BRCA2 mutations in Finnish breast cancer families: evidence for additional susceptibility genes. Hum Mol Genet 1997:6:2309-15.

4 Huusko P, Pääkkönen K, Launonen V, Pöyhönen M, Blanco G, Kauppila A, Puistola U, Kiviniemi H, Kujala $M$, Leisti J, Winqvist R. Evidence of founder mutations in Finnish BRCA1 and BRCA2 families. Am J Hum Genet 1998;62:1544-8

5 Nathanson KL, Weber BL. "Other" breast cancer susceptibility genes: searching for more holy grail. Hum Mol Genet 2001;10:715-20.

6 The CHEK2-Breast Cancer Consortium. Low-penetrance susceptibility to breast cancer due to CHEK2(*)1100delC in noncarriers of BRCA1 or BRCA2 mutations. Nat Genet 2002:31:55-9.

7 Pharoah PDP, Antoniou A, Bobrow M, Zimmern RL, Easton DF, Ponder BAJ. Polygenic susceptibility to breast cancer and implications for prevention. Nat Genet 2002;31:33-6.

8 Petrini JH. The mammalian Mre 11-Rad50-Nbs 1 protein complex: integration of functions in the cellular DNA-damage response. Am J Hum Genet 1999;64:1264-9.

9 Carney JP, Maser RS, Olivares H, Davis EM, LeBeau ML, Yates III JR, Hays L, Morgan WF, Petrini JHJ. The hMre11/hRad50 protein complex and Nijmegen breakage syndrome: linkage of double-strand break repair to the cellular DNA damage response. Cell 1998;93:477-86.

10 Tauchi H, Kobayashi J, Morishima K, van Gent DC, Shiraishi T, Verkaik NS van Heems D, Ito E, Nakamura A, Sonoda E, Takata M, Takeda S, Matsuura S Komatsu K. Nbs 1 is essential for DNA repair by homologous recombination in higher vertebrate cells. Nature 2002;420:93-8.

11 Zhao S, Weng YC, Yuan SS, Lin YT, Hsu HC, Lin SC, Gerbino E, Song MH, Zdzienicka MZ, Gatti RA, Shay JW, Ziv Y, Shiloh Y, Lee EY. Functional link between ataxia-telangiectasia and Nijmegen breakage syndrome gene products. Nature 2000:405:473-7.

12 Buscemi G, Savio C, Zannini L, Micciche F, Masnada D, Nakanishi M, Tauchi H, Komatsu K, Mizutani S, Khanna K, Chen P, Concannon P, Chessa L, Delia D. Chk2 activation dependence on Nbs1 after DNA damage. Mol Cell Biol 2001;21:5214-22.

13 Girard PM, Riballo E, Begg AC, Waugh A, Jeggo PA. Nbs 1 promotes ATM dependent phosphorylation events including those required for $\mathrm{Gl} / \mathrm{S}$ arrest. Oncogene 2002;21:4191-9.

14 D'Amours D, Jackson SP. The Mre 11 complex: at the crossroads of DNA repair and checkpoint signalling. Nat Rev Mol Cell Biol 2002;3:317-27. 
15 Zhu X-D, Kuster B, Mann M, Petrini JHJ, de Lange T. Cell-cycle-regulated association of RAD50/MRE1 1/NBS1 with TRF2 and human telomeres. Nat Genet 2000;25:347-52.

16 Desai-Mehta A, Cerosaletti KM, Concannon P. Distinct functional domains of nibrin mediate Mre 11 binding, focus formation, and nuclear localization. Mol Cell Biol 2001;21:2184-91.

17 Tauchi H, Kobayashi J, Morishima KI, Matsuura S, Nakamura A, Shiraishi T, Ito E, Masnada D, Delia D, Komatsu K. The forkhead-associated domain of NBS1 is essential for nuclear foci formation after irradiation but not essential for hRAD50-hMRE1 1-NBS1 complex DNA repair activity. J Biol Chem $2001 ; 276: 12-15$.

18 Bressan DA, Olivares HA, Nelms BE, Petrini JH. Alteration of $\mathrm{N}$-terminal phosphoesterase signature motifs inactivates Saccharomyces cerevisiae Mre11. Genetics 1998;150:591-600.

19 Hopfner KP, Karcher A, Shin DS, Craig L, Arthur LM, Carney JP, Tainer JA. Structural biology of Rad50 ATPase: ATP-driven conformational control in DNA double-strand break repair and the ABC-ATPase superfamily. Cell 2000;101:789-800

20 Hopfner KP, Karcher A, Craig L, Woo IT, Carney JP, Tainer JA. Structural biochemistry and interaction architecture of the DNA double-strand break repair Mre1 1 nuclease and Rad50-ATPase. Cell 2001;105:473-85.

21 Varon R, Vissinga C, Platzer M, Cerosaletti KM, Chrzanowska KH, Saar K, Beckmann G, Seemanova E, Cooper PR, Nowak NJ, Stumm M,

Weemaes CMR, Gatti RA, Wilson RK, Digweed M, Rosenthal A, Sperling K, Concannon P, Reis A. Nibrin, a novel DNA double-strand break repair protein, is mutated in Nijmegen breakage syndrome. Cell 1998;93:467-76.

22 Zhao S, Renthal W, Lee EY. Functional analysis of FHA and BRCT domains of NBS1 in chromatin association and DNA damage responses. Nucleic Acids Res 2002;30:4815-22.

23 Hopfner KP, Craig L, Moncalian G, Zinkel RA, Usui T, Owen BA, Karcher A, Henderson B, Bodmer JL, MCMurray CT, Carney JP, Petrini JH, Tainer JA. The Rad50 zinc-hook is a structure joining Mre 11 complexes in DNA recombination and repair. Nature 2002;418:562-6.

24 Dong Z, Zhong Q, Chen P-L. The Nijmegen breakage syndrome protein is essential for Mrel 1 phosphorylation upon DNA damage. J Biol Chem 1999:274:19513-26.

25 Zhong Q, Chen CF, Li S, Chen Y, Wang CC, Xiao J, Chen PL, Sharp ZD, Lee WH. Association of BRCA1 with the hRad50-hMre11-p95 complex and the DNA damage response. Science 1999;285:747-50.

26 Wang Y, Cortez D, Yazdi P, Neff N, Elledge SJ, Qin J. BASC, a super complex of BRCA1-associated proteins involved in the recognition and repair of aberrant DNA structures. Genes Dev 2000;14:927-39.

27 Stewart GS, Maser RS, Stankovic T, Bressan DA, Kaplan MI, Jaspers NG, Raams A, Byrd PJ, Petrini JH, Taylor AM. The DNA double-strand break repair gene hMRE1 1 is mutated in individuals with an ataxia-telangiectasialike disorder. Cell 1999:99:577-87.

28 Shiloh Y. Ataxia-telangiectasia and the Nijmegen breakage syndrome: related disorders but genes apart. Annu Rev Genet 1997;31:635-62.

29 Bender CF, Sikes ML, Sullivan R, Huye LE, Le Beau MM, Roth DB, Mirzoeva OK, Oltz EM, Petrini JHJ. Cancer predisposition and hematopoietic failure in RAD50 ${ }^{\mathrm{S} / \mathrm{S}}$ mice. Genes Dev 2002;16:2237-51.

30 Gorski B, Debniak T, Masojc B, Mierzejewski M, Medrek K, Cybulski C, Jakubowska A, Kurzawski G, Chosia M, Scott R, Lubinski J. Germline 657del5 mutation in the NBS1 gene in breast cancer patients. Int J Cancer 2003; 106:379-81.

31 Allinen M, Huusko P, Mäntyniemi S, Launonen V, Winqvist R. Mutation analysis of the CHK2 gene in families with hereditary breast cancer. Br J Cancer 2001;85:209-12.

32 Rapakko K, Allinen M, Syriäkoski K, Vahteristo $P$, Huusko $P$, Vähäkangas $K$, Eerola H, Kainu T, Kallioniemi O-P, Nevanlinna H, Winqvist R. Germline TP53 alterations in Finnish breast cancer families are rare and occur at conserved mutation-prone sites. Br J Cancer 2001;84:116-19.

33 Ganguly A. An update on conformation sensitive gel electrophoresis. Hum Mutat 2002;19:334-42.

34 Xiao Y, Weaver DT. Conditional gene targeted deletion by Cre recombinase demonstrates the requirement for the double-strand break repair Mre 1 lprotein in murine embryonic stem cells. Nucleic Acids Res 1997;25:2985-91

35 Luo G, Yao MS, Bender CF, Mills M, Bladl AR, Bradley A, Petrini JH. Disruption of mRad50 causes embryonic stem cell lethality, abnormal embryonic development, and sensitivity to ionizing radiation. Proc Natl Acad Sci USA 1999;96:7376-81.

36 Zhu J, Petersen S, Tessarollo L, Nussenzweig A. Targeted disruption of the Nijmegen breakage syndrome gene NBS1 leads to early embryonic lethality in mice. Curr Biol 2001;11:105-9.

37 Pitts SA, Kullar HS, Stankovic T, Stewart GS, Last Jl, Bedenham T, Armstrong SJ, Piane M, Chessa L, Taylor AM, Byrd PJ. hMRE1 1: genomic structure and a null mutation identified in a transcript protected from nonsense-mediated mRNA decay. Hum Mol Genet 2001;10:1155-62.

38 Connelly JC, Leach DR. Tethering on the brink: the evolutionarily conserved Mre11-Rad50 complex. Trends Biochem Sci 2002;27:410-18.

39 Varon R, Reis A, Henze G, von Einsiedel HG, Sperling K, Seeger K. Mutations in the Nijmegen breakage syndrome gene (NBS1) in childhood acute lymphoblastic leukemia (ALL). Cancer Res 2001;61:3570-2.

40 Cerosaletti KM, Concannon P. The Nibrin FHA and BRCT domains are both required for nuclear focus formation and phosphorylation. J Biol Chem 2003; 278:21944-51.

41 Fodde R, Smits R. A matter of dosage. Science 2002;298:761-3.

42 Maser RS, Zinkel R, Petrini JH. An alternative mode of translation permits production of a variant NBS1 protein from the common Nijmegen breakage syndrome allele. Nat Genet 2001;27:417-21.

43 Dolganov GM, Maser RS, Novikov A, Tosto L, Chong S, Bressan DA, Petrini JHJ. Human Rad50 is physically associated with human Mre 11 : identification of a conserved multiprotein complex implicated in recombinational DNA repair. Mol Cell Biol 1996:16:4832-41.

44 Nathanson KL, Shugart YY, Omaruddin R, Szabo C, Goldgar D, Rebbeck TR, Weber BL. CGH-targeted linkage analysis reveals a possible BRCA1 modifier locus on chromosome 5q. Hum Mol Genet 2002;1 1:1327-32.

45 Peltonen L, Jalanko A, Varilo T. Molecular genetics of the Finnish disease heritage. Hum Mol Genet 1999;8:1913-23.

46 Vahteristo P, Bartkova J, Eerola H, Syrjäkoski K, Ojala S, Kilpivaara O, Tamminen A, Kononen J, Aittomäki K, Heikkilä P, Holli K, Blomqvist C, Bartek J, Kallioniemi OP, Nevanlinna H. A CHEK2 genetic variant contributing to a substantial fraction of familial breast cancer. Am J Hum Genet 2002;71:432-8. 